\title{
Regulation of Macrophage Function by Interferon- $\gamma$ \\ Somatic Cell Genetic Approaches in Murine Macrophage Cell Lines to Mechanisms of Growth Inhibition, the Oxidative Burst, and Expression of the Chronic Granulomatous Disease Gene
}

\author{
Michael Goldberg, Linda S. Belkowski, and Barry R. Bloom \\ Departments of Microbiology and Immunology, and Cell Biology, Albert Einstein College of Medicine, Bronx, New York 10461
}

\begin{abstract}
The importance of oxidative cytocidal mechanisms of phagocytic cells in immune protection against microbial pathogens is uniquely revealed by chronic granulomatous disease (CGD), a genetic deficiency disease of man. This cytocidal response in mononuclear phagocytes is principally regulated by IFN- $\boldsymbol{\gamma}$. A somatic cell genetic approach was taken to select oxidative variants from a cloned murine macrophage cell line, J774.16, which formally permitted us to dissociate three regulatory effects of IFN- $\gamma$ on these cells: the antiproliferative effect, the antiviral effect, and production of superoxide anion. Half of the variants defective in $\mathrm{O}_{2}^{-}$production after phorbol myristate acetate stimulation were also resistant to the antiproliferative effects of IFN- $\gamma$. This result suggests that IFN- $\gamma$-induced growth inhibition and production of cytocidal oxygen intermediates are mediated via a common pathway. The somatic cell genetic approach has allowed us to develop in vitro macrophage models for several forms of CGD. One variant characterized in detail, D9, was unable to produce superoxide after stimulation by phorbol esters. At the molecular level, Northern blot analysis revealed that the mRNA encoding the large subunit of the putative CGD gene product, cytochrome $b_{558}$, was absent in this variant. Another class of variants constitutively unable to produce $\mathrm{O}_{2}^{-}$or the cytochrome $b_{558}$ mRNA could be induced to do so by IFN- $\gamma$. These somatic mutants may be useful models in clarifying the role of the CGD gene product and its regulation in the production of cytocidal oxygen intermediates. (J. Clin. Invest. 1990. 85:563-569.) superoxide anion - antiproliferative activity - vesicular stomatitis virus • chronic granulomatous disease $\cdot$ cytocidal oxygen intermediates $\bullet$ antiviral activity
\end{abstract}

\section{Introduction}

Mononuclear phagocytes play an important role in the immune response against infectious agents, indirectly by processing and presenting antigens to $T$ cells, and directly by phagocytosing and killing microbial pathogens by both oxidative and nonoxidative mechanisms $(1,2)$. IFN- $\gamma$ is the principal lymphokine involved in regulating macrophage function, activating primary macrophages to become competent to produce oxidative cytocidal intermediates (3), augmenting expression of major histocompatibility class I and II antigens $(4,5)$ and Fc

Address reprint requests to Dr. B. R. Bloom, Department of Microbiology/Immunology, Albert Einstein College of Medicine, Yeshiva University, 1300 Morris Park Ave., Bronx, NY 10461.

Received for publication 15 August 1988 and in revised form 27 September 1989.

J. Clin. Invest.

(c) The American Society for Clinical Investigation, Inc. 0021-9738/90/02/0563/07 \$2.00

Volume 85, February 1990, 563-569 receptors (6), inducing an antiviral state (7), and exerting potent antiproliferative effects on transformed macrophage cell lines $(8)$.

The importance of oxidative cytocidal mechanisms in protection against microbial infection is underscored by the consequences of chronic granulomatous disease (CGD), ${ }^{1}$ a genetic deficiency disease of man in which the oxidative burst of PMN and macrophages after endocytosis of bacteria and parasites is defective $(9,10)$. CGD is a genetically heterogeneous group of disorders with both $\mathrm{X}$-linked inheritance $(66 \%)$ and autosomal recessive inheritance (33\%) (11-13). Both X-linked and autosomal recessive forms of CGD can be further classified according to whether or not a membrane-associated cytochrome $b_{558}$ is present in the phagocytic cells (14). Both the 91- and $22-\mathrm{kD}$ components of the cytochrome $b_{558}$ have recently been cloned and sequenced $(15,16)$. Although important information has been derived from the study of primary cells from patients with CGD, there are limitations in the number of such cells available for biochemical and molecular genetic analyses. Because of the potential advantages of continuous cell lines and the power of somatic cell genetic approaches to develop mutant cell models for human genetic diseases, we have for some years studied cloned murine macrophage cell lines. One such clone, J774.16, can be stimulated to oxidize glucose through the hexose monophosphate shunt to produce superoxide and hydrogen peroxide and to kill intracellular parasites, comparable to the IFN- $\boldsymbol{\gamma}$-induced activation of primary macrophages (17-19). This cell line was instrumental in establishing that one of the earliest biochemical changes in macrophages exposed to such diverse stimuli as aggregated IgG and phorbol myristate acetate (PMA) was the rapid phosphorylation of a common set of proteins through the action of protein kinase C (PKC) (20).

In this study, we have used a somatic cell genetic approach to isolate variants in oxidative metabolism from the J774.16 cell line, with two aims: $(a)$ To analyze whether the respiratory burst, the antiproliferative and antiviral effects regulated by IFN- $\gamma$ in macrophages, are mediated by the same or different intracellular pathways; and (b) To develop an in vitro macrophage model useful for studying the regulation of the CGD gene, particularly by gene transfer experiments, to analyze cellular and regulatory requirements for its function in the production of oxidative intermediates.

\section{Methods}

Reagents. PMA was obtained from Consolidated Midland Corporation, Brewster, NY. Aliquots of PMA ( $10 \mathrm{mg} / \mathrm{ml}$ in DMSO) were kept at $-90^{\circ} \mathrm{C}$ and diluted 10 -fold with DMSO immediately before use.

1. Abbreviations used in this paper: $\mathrm{CGD}$, chronic granulomatous disease; NBT, nitroblue tetrazolium; PKC, protein kinase C; VSV, vesicular stomatis virus. 
Nitroblue tetrazolium (NBT), NP-40, and Tris were purchased from Sigma Chemical Co., St. Louis, MO.

IFNs. Recombinant Escherichia coli-derived murine IFN- $\gamma$ was kindly provided by Genentech Inc. (South San Francisco, CA) and had a specific activity of $1.24 \times 10^{7} \mathrm{U} / \mathrm{mg}$. Murine IFN- $\alpha$ was obtained from Lee Biomolecular Research Laboratories, Inc., San Diego, CA (catalogue 22061) and had a specific activity of $2.7 \times 10^{6} \mathrm{U} / \mathrm{mg}$. IFN activity was assayed by the inhibition of cytopathic effects of encephalomyocarditis virus on $\mathrm{L}$ cells in microtiter wells. IFN activity was routinely titered once a month to monitor any loss of activity.

Cells. Murine macrophage-like cloned cell lines J774.16 and variant clones were cultured and cloned as single cells as described previously (17). The mouse hepatoma cell line, $E_{3}$, was grown in DME supplemented with. 10\% heat-inactivated FCS (Gibco Laboratories, Grand Island, NY), 5\% NCTC, and 1\% nonessential amino acids and trypsinized twice a week. Primary rat embryo fibroblasts were cultured in DME supplemented with 10\% FCS. Bac1.2.5 is an origin-defective SV40-transformed murine macrophage cell line kindly provided by Dr. Betty Diamond of Albert Einstein College of Medicine.

Selection procedure for variants in oxidative metabolism. The procedure employed is a selection against macrophage clones capable of reducing NBT to the polymer, formazan, which is toxic to the cells as previously described (17). Six independent pools of J774.16 cells were allowed to grow in $100-\mathrm{cm}^{2}$ petri dishes (Falcon Labware, Oxnard, CA) for 3-4 d until confluent, such that there were $\sim 1-2 \times 10^{7}$ cells/pool per dish. These cells were incubated with PMA and NBT $(6 \mu \mathrm{g} / \mathrm{ml}$ and $20 \mathrm{mg} / \mathrm{ml}$, respectively) in Krebs Ringer phosphate glucose solution containing $25 \% \mathrm{FCS}$, for $1 \mathrm{~h}$ at $37^{\circ} \mathrm{C}$. The cells were carefully washed with warm Krebs Ringer phosphate glucose solution containing $25 \%$ FCS to remove as much NBT and PMA as possible, and viable cells were allowed to grow up for $1 \mathrm{wk}$. After three successive selections in NBT and PMA over a 3-wk period, cells of each pool were cloned in soft agarose for the isolation of independent colonies. These clones were then tested for their ability to reduce NBT after appropriate stimulation with PMA. Clones J774.16 and mutant D9 have been cloned in agarose at a seeding density of 2,000 cells $/ 60-\mathrm{cm}^{2}$ dish at least four times over the past $2.5 \mathrm{yr}$, and they have continued to maintain their phenotype. Using the same selection procedure, oxidative variants (2-5, 5-12) were derived from an independent subclone of J774.16 that was previously tagged for other purposes with a defective retrovirus containing a neo marker. Reduction of NBT and ferricytochrome $c$ by macrophage clones was performed as previously described (17).

Growth curves. Cells in $\log$ phase were seeded $\left(7.5 \times 10^{3}\right.$ cells $/ 0.15$ $\mathrm{ml}$ ) in triplicate in 96-well plates (Linbro, Flow Laboratories, Hamden, CT) in the absence or presence of the various IFNs and PMA. At the time intervals indicated, $0.025 \mathrm{ml}$ of $\left[{ }^{3} \mathrm{H}\right]$ thymidine at $0.04 \mathrm{mCi} / \mathrm{ml}$ was added per well (final concentration of $1 \mu \mathrm{Ci} /$ well). After a 45-min incubation, the cells were lysed with $0.05 \mathrm{ml}$ of $0.45 \%$ NP-40 in PBS (5-10 $\mathrm{min}$ ), while rotating on an orbital gyrator. Nuclei were harvested onto glass filter paper, dried, and counted with Liquiscint (National Diagnostics, Inc., Somerville, NJ) for $1 \mathrm{~min}$ in a liquid scintillation counter. Results for each experimental point are derived from the mean of triplicate wells. (Individual wells varied generally less than 1 SD from the mean.) Preliminary experiments indicated that the inhibition of thymidine incorporation by IFN- $\alpha$ and IFN- $\gamma$ paralleled the actual growth inhibition ascertained by counting viable cells excluding trypan blue with a hemocytometer.

Viruses. The Indiana (HRC) serotype of vesicular stomatis virus (VSV) was prepared in chicken embryo fibroblasts, clarified by centrifugation $(1,000 \mathrm{~g}, 10 \mathrm{~min})$, and had a titer of $3.0 \times 10^{8} \mathrm{pfu} / \mathrm{ml}$. The stock was divided into aliquots, frozen at $-70^{\circ} \mathrm{C}$, and diluted into macrophage culture medium before use. Infection of cell lines with viruses and quantitation of viral yields were performed as previously reported (21).

\section{Results}

Isolation of variants defective in the respiratory burst. The initial question considered was whether the oxidative burst and the antiproliferative effects of IFN- $\gamma$ were regulated via a common pathway. The strategy used to address this question was to derive variants defective in the oxidative burst and test them for their sensitivity to growth inhibition mediated by IFN- $\gamma$. The existence of variants defective in both the respiratory burst and growth inhibition mediated by IFN- $\gamma$ is evidence that these effects may be regulated via a common pathway. In order to select variants from the $\mathbf{J 7 7 4 . 1 6}$ clone defective in oxidative metabolism, we used a suicide-selection strategy similar to that described previously (17), based on the observation that reduced formazan, the product of the reaction between the $\mathrm{O}_{2}^{-}$anion and the dye, NBT, is toxic to cells. This toxicity permits the selection of variants incapable of reducing NBT, presumably due to the failure to produce superoxide after appropriate stimulation. Six independent pools (A-F) of J774.16 cells (1-2 $\times 10^{7}$ cells/pool) were screened by this procedure for oxidative variants. After three successive selections in NBT and PMA over a 3-wk period, cells of each pool were cloned as single cells in soft agarose for the isolation of independent colonies. These clones were then retested for their ability to reduce NBT and for their sensitivity to the antiproliferative effects of IFN- $\gamma$. All clones tested $(n=5)$ from at least two independent pools of cells that still maintained their ability to reduce NBT were sensitive to the antiproliferative effects of IFN- $\gamma$. In contrast, four NBT-negative clones from independent groups, and $\sim 50 \%$ of all the NBTnegative clones tested, were resistant to the antiproliferative effects of IFN- $\gamma$ after $64 \mathrm{~h}$ (Fig. 1). In fact, some of the growth-resistant clones appeared to be slightly stimulated by IFN- $\gamma$. The finding that some variants were both defective in the production of superoxide and resistant to the antiprolifer-

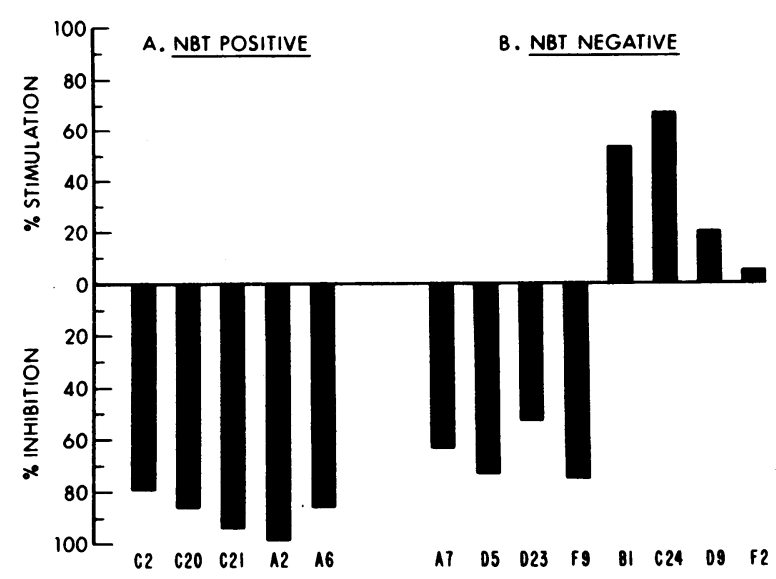

Figure 1. Effect of IFN- $\gamma$ on the proliferation of macrophage clones. Cells were seeded in triplicate in the presence or absence of IFN- $\gamma$ $(650 \mathrm{IU} / \mathrm{ml})$. After $64 \mathrm{~h}$ of incubation, the cells were pulsed for 45 min with tritiated thymidine and harvested. Results are shown as the percent stimulation or percent inhibition of growth by IFN- $\gamma$ as compared with medium alone. Each clone is represented by an alphanumeric code at the bottom of each bar in which each letter A-F represents an independently selected pool of cells with the numeral referring to a particular clone in that group. The number of counts per minute incorporated of $\left[{ }^{3} \mathrm{H}\right] \mathrm{TdR}$ in the absence of IFN- $\gamma$ was 5.6, 2.3, 4.6, 4.6, 4.0, 8.2, 11.8, 10.0, 17.1, 4.0, 4.3, 4.5, 3.1, × $10^{4}$ for clones C2, C20, C21, A2, A6, A7, D5, D23, F9, B1, C24, D9, and $\mathrm{F} 2$, respectively. $(A)$ Clones that maintained their ability to reduce NBT even after the selective procedure. $(B)$ Clones that were oxidative variants as defined by their inability to reduce NBT. 
Table I. Reduction of Viral Yields in Parental and Oxidative Variant Cell Lines

\begin{tabular}{|c|c|c|c|c|c|}
\hline \multirow[b]{2}{*}{ Clone } & \multicolumn{3}{|c|}{ VSV yields } & \multicolumn{2}{|c|}{$\begin{array}{c}\text { Reduction of viral } \\
\text { yields }\end{array}$} \\
\hline & - & IFN- $\gamma$ & IFN- $\alpha$ & IFN- $\gamma$ & IFN- $\alpha$ \\
\hline & & $p f u / m l$ & & & \\
\hline J774.16 & $2.8 \times 10^{7}$ & $1.5 \times 10^{3}$ & $1.2 \times 10^{3}$ & $\sim 10^{4}$ & $\sim 10^{4}$ \\
\hline $\mathrm{C} 21$ & $1.1 \times 10^{6}$ & $7.8 \times 10^{2}$ & $2.2 \times 10^{2}$ & $\sim 10^{3}$ & $\sim 10^{4}$ \\
\hline D23 & $3.8 \times 10^{6}$ & $1.4 \times 10^{3}$ & $<10^{2}$ & $\sim 10^{3}$ & $>10^{4}$ \\
\hline B1 & $3.9 \times 10^{6}$ & $8.2 \times 10^{3}$ & $<10^{2}$ & $\sim 10^{2}$ & $>10^{4}$ \\
\hline $\mathrm{C} 24$ & $5.0 \times 10^{6}$ & $2.5 \times 10^{3}$ & $1.3 \times 10^{3}$ & $\sim 10^{3}$ & $\sim 10^{3}$ \\
\hline D9 & $5.3 \times 10^{7}$ & $2.5 \times 10^{3}$ & $5.0 \times 10^{3}$ & $\sim 10^{4}$ & $\sim 10^{4}$ \\
\hline $2-5$ & $1.1 \times 10^{7}$ & $7.6 \times 10^{4}$ & $4.8 \times 10^{2}$ & $\sim 10^{2}$ & $\sim 10^{4}$ \\
\hline $5-12$ & $1.6 \times 10^{7}$ & $1.3 \times 10^{5}$ & $1.7 \times 10^{3}$ & $\sim 10^{2}$ & $\sim 10^{4}$ \\
\hline
\end{tabular}

Cells $\left(2.5 \times 10^{5} \mathrm{IU} / \mathrm{ml}\right)$ were incubated for $21 \mathrm{~h}$ in medium alone $(-)$, IFN- $\gamma(500 \mathrm{IU} / \mathrm{ml})$, or IFN- $\alpha(100 \mathrm{IU} / \mathrm{ml})$. They were then infected with VSV and cultured for an additional $24 \mathrm{~h}$. The supernatants were collected and assayed for viral yields on Vero cell monolayers.

ative effects of IFN- $\gamma$ suggests that both of these effects are regulated by a common intracellular pathway. The existence of variants growth-inhibited by IFN- $\gamma$ but unable to produce $\mathrm{O}_{2}^{-}$indicates that mechanisms other than $\mathrm{O}_{2}^{-}$toxicity must be responsible for the antiproliferative effects of IFN- $\gamma$. These latter variants also indicate that this common pathway must diverge before final effector functions, i.e., the production of cytocidal intermediates and growth inhibition, respectively. Further, since the oxidative/antiproliferative variants remain fully protected against VSV infection by both IFN- $\gamma$ and IFN- $\alpha$, functional receptors for both IFNs must exist on these cells (Table I). Thus, the receptor-triggered pathway mediating the antiviral response must diverge earlier than the common oxidative/antiproliferative branch. Finally, since the only known molecular function of PMA is to bind and activate PKC (22), and our previous work showed that transcriptional activation of genes in a human macrophage cell line by IFN- $\gamma$ is blocked by PKC inhibitors (23), the present results suggest that a PKC-mediated pathway is involved in the antiproliferative effects of IFN- $\gamma$ in these cells.

Molecular analysis of a novel oxidative variant. One of the NBT-negative clones resistant to the antiproliferative effects of IFN- $\gamma$, D9, was characterized in greater detail. Fig. 2 illustrates its inability to reduce NBT after stimulation with PMA, as compared with the parental line. This was confirmed by the more precise measurement of $\mathrm{O}_{2}^{-}$using SOD-inhibitable cytochrome $c$ reduction, as reported previously (17). Clone J774.16 produced $\sim 1 \mathrm{nmol} / \mathrm{min}$ per $10^{6}$ cells of $\mathrm{O}_{2}^{-}$, while clone D9 produced $<0.03 \mathrm{nmol} / \mathrm{min}$, the limit of detection (Fig. 3). When the growth characteristics of parental J774.16 and D9 cells were compared in the presence of PMA and IFN- $\gamma$ (Fig. 4), we observed that, whereas the parental line was sensitive to the antiproliferative effects of IFN- $\gamma$ and PMA, the D9 variant grew readily in both. Thus, if one assumes that
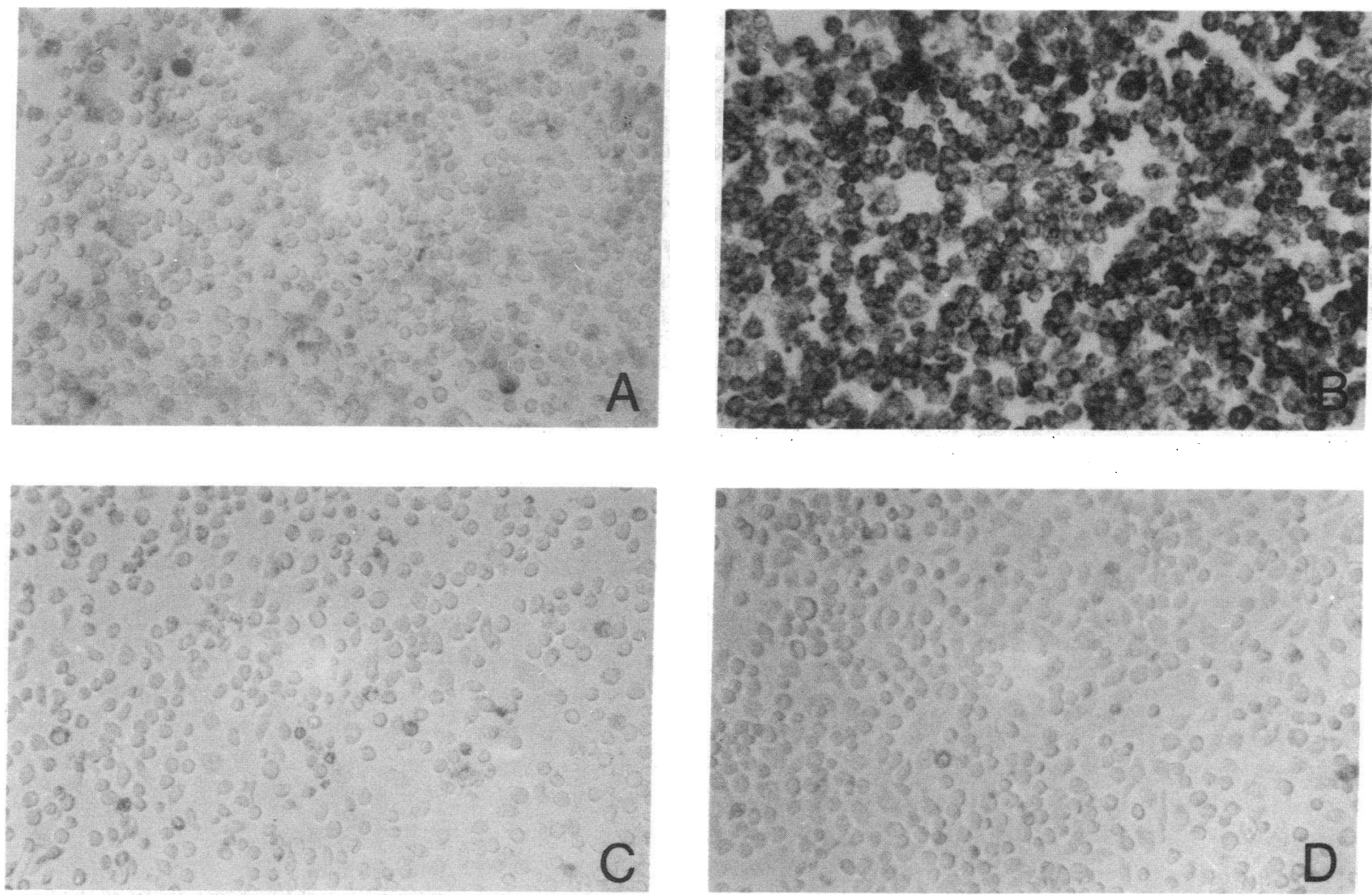

Figure 2. NBT reduction in $\mathrm{J} 774.16$ and $\mathrm{D} 9$ cells. $\mathrm{J} 774.16$ cells $(A, B)$ and $\mathrm{D} 9$ cells $(C, D)$ were plated in 96 -well tissue culture plates $\left(5 \times 10^{4}\right.$ cells/well) before NBT solution containing either carrier alone, DMSO $(A, C)$, or PMA $(B, D)$ was added. After a 45 -min incubation at $37^{\circ} \mathrm{C}$, the cells were washed with PBS and then photographed. 


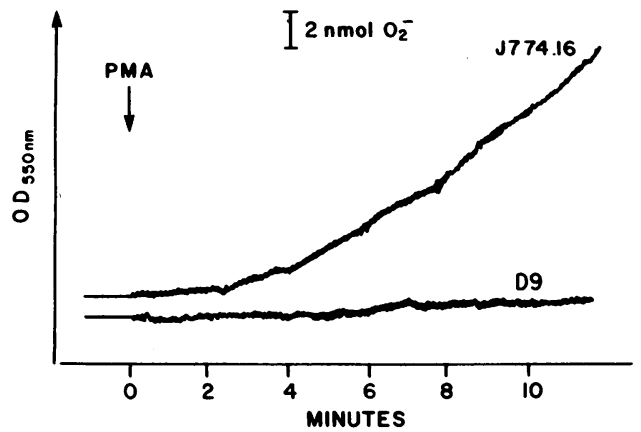

Figure 3. $\mathrm{O}_{2}^{-}$production in parental and $\mathrm{D} 9$ variant. Superoxide was determined by spectrophotometric assay of cytochrome $c$ reduction. Incubation with SOD $(30 \mu \mathrm{g} / \mathrm{ml})$ totally abrogated reduction of cytochrome $c$ (data not shown).

these cells have a single mutation, simultaneous failure of this variant to be growth inhibited by PMA or IFN- $\gamma$ supports the view that the PMA-induced and IFN- $\gamma$ antiproliferative effects are mediated, by a pathway involving PKC. Until the precise nature of the mutation is elucidated, we cannot formally exclude the possibility that IFN- $\gamma$ acts at a step distal to PKC in that pathway.

Orkin and colleagues recently reported that the CGD 91-kD subunit gene transcript is induced by both PMA and IFN- $\gamma$ in the THP-1 human monocytic leukemia cell line (24). Since the D9 variant was unresponsive to both PMA and IFN- $\gamma$, the possibility was explored that its inability to produce superoxide was similarly due to a defective $91-\mathrm{kD}$ subunit gene or its regulation. Consequently, RNA preparations from the parental and D9 variant were analyzed by Northern blots (21) for production of the murine homologue of the $91-\mathrm{kD}$ subunit transcript (Fig. 5). The $91-\mathrm{kD}$ subunit gene is constitutively transcribed in the parental $\mathbf{J 7 7 4} .16$ clone. In contrast, no transcript from this locus in the D9 variant could be observed, even after long exposure times. Southern analysis using a murine probe encoding $1.4 \mathrm{~kb}$ of the $5^{\prime}$ end of the gene for the 91-kD subunit revealed no detectable changes in its DNA organization in the D9 variant (data not shown).
Using the same selection procedure, additional variants were derived that were unable to produce $\mathrm{O}_{2}^{-}$in response to PMA. Two of these variants could be induced by treatment with IFN- $\gamma$ to reduce NBT and cytochrome $c$ after appropriate stimulation (clones 2-5 and 5-12) (Table II). Both clones were found to be growth-inhibited by IFN- $\gamma$ (Table II) and protected against VSV lysis (Table I). Neither clone constitutively expressed mRNA for the 91-kD subunit, but transcripts were detected after treatment with IFN- $\gamma$. This is in contrast to clone D9, which could not be induced to produce $\mathrm{O}_{2}^{-}$or the transcript by IFN- $\gamma$ (Fig. 6). These mutants thus bear an analogy to cells of patients with the X-linked form of CGD that is correctable by treatment with $\operatorname{IFN}-\gamma(25,26)$.

\section{Discussion}

The development of macrophage somatic cell variants described in this paper enabled us to address the question of whether the pleiotropic effects of IFN- $\gamma$ on macrophages are mediated by a single or multiple pathways. The experimental results formally dissociate three effects of IFN- $\gamma$ on effector functions of the macrophage: the production of $\mathrm{O}_{2}^{-}$, the antiproliferative effect, and the antiviral activity. The mutants have provided evidence for the first time that the regulation of two of these parameters by IFN- $\gamma$, the respiratory burst and inhibition of cell growth, occur via a common pathway. Specifically, $50 \%$ of the variants defective in their oxidative metabolism were resistant to the antiproliferative effects of IFN- $\gamma$. This association is unlikely to be explained by inhibition of cell growth by toxic oxygen metabolites per se, since at least half of the variants unable to produce reactive oxygen intermediates remained fully growth-inhibited by IFN- $\gamma$. The addition of superoxide dismutase $(30 \mu \mathrm{g} / \mathrm{ml})$, in excess of the amount required to abolish all detectable $\mathrm{O}_{2}^{-}$, failed to affect the inhibition of growth by IFN- $\gamma$ in the parental clone (data not shown).

The selection procedure for the isolation of oxidative variants is sufficiently cumbersome as to preclude a fluctuation analysis to determine the true mutation frequency of the oxidative variants. In our previous studies using the same selection procedure, we estimated that the frequency of obtaining

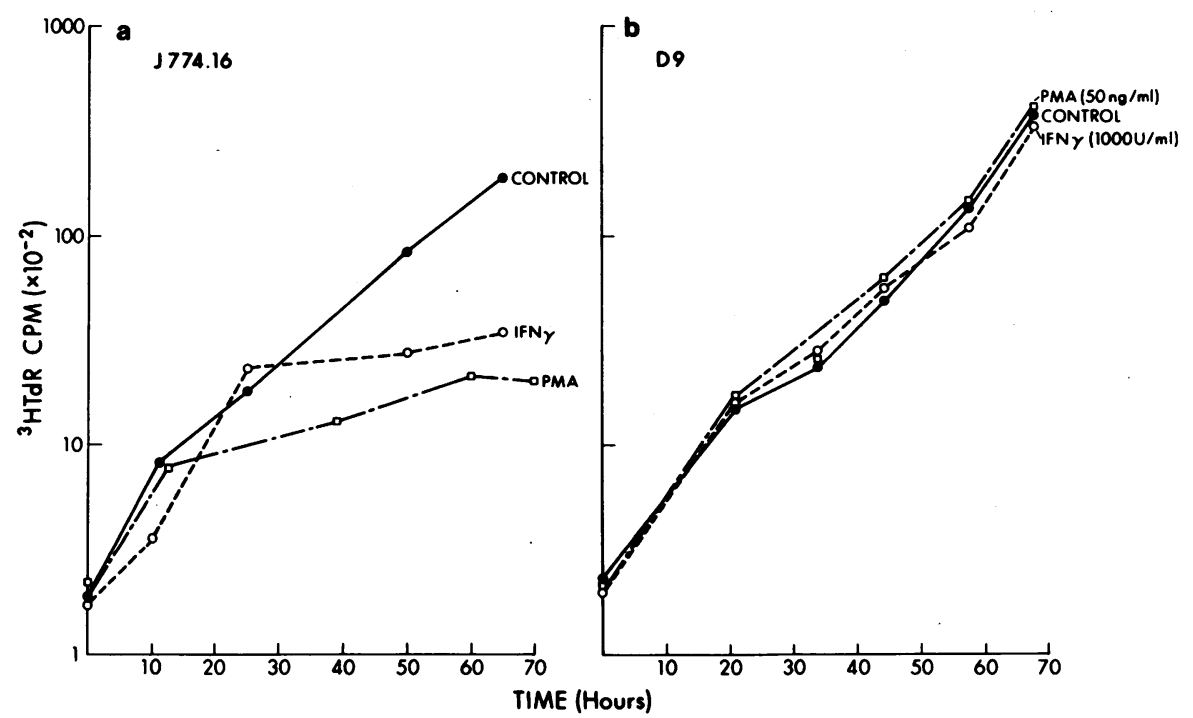

Figure 4. Effect of IFN- $\gamma$ and PMA on the growth of J774.16 and D9 cells. Cells were seeded at a density of $7.5 \times 10^{3}$ cells/well in $\bullet$, medium alone; $O, \operatorname{IFN}-\gamma(1,000$ IU $/ \mathrm{ml})$; or $\square$, PMA $(50 \mathrm{ng} / \mathrm{ml})$. At the various times indicated the cells were pulsed with $\left[{ }^{3} \mathrm{H}\right] \mathrm{TdR}$ and harvested. Each point represents the average of triplicate wells. 


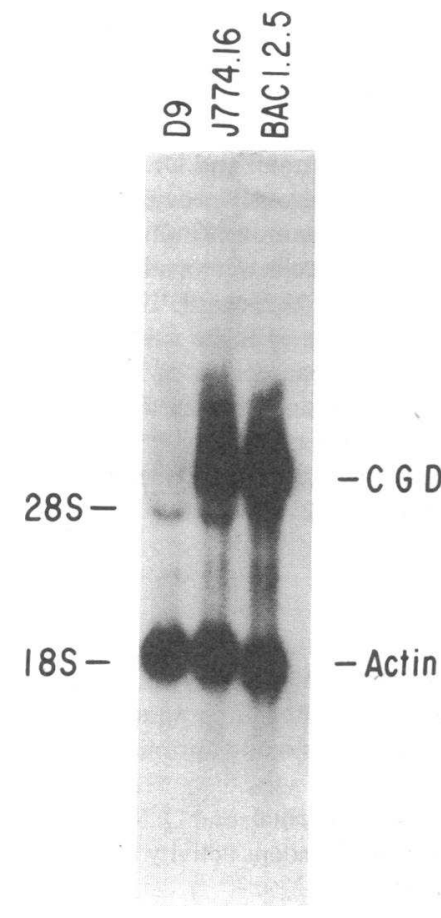

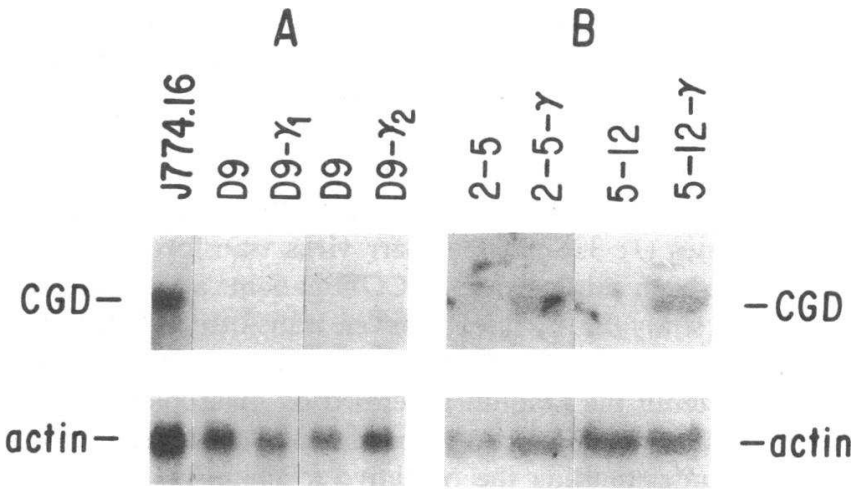

Figure 6. Induction of CGD mRNA by IFN- $\gamma(500 \mathrm{IU} / \mathrm{ml})$ in oxidative variants. D9- $\gamma_{1}=$ D9 cells treated with IFN- $\gamma$ for $9 \mathrm{~h}$. D9- $\gamma_{2}$ $=\mathrm{D} 9$ cells treated with IFN- $\gamma$ for $3 \mathrm{~d}$. $2-5-\gamma$ and 5-12- $\gamma$ were treated with IFN- $\gamma$ for $2 \mathrm{~d}$.

after IFN- $\boldsymbol{\gamma}$-treatment (28). We have recently presented evidence in the human macrophage cell line, U937, that transcriptional activation of many, but not all, IFN- $\gamma$-inducible genes occurs by a PKC-dependent pathway (23).

Although multiple mechanisms for the microbicidal activities of mononuclear phagocytes have been proposed, the importance of reactive oxygen intermediates is underscored by CGD, which is characterized by repeated infection and an inability of phagocytic cells to kill intracellular pathogens (10). Both X-linked and autosomally recessive forms of CGD have been described (reviewed in references 13 and 14). The majority of patients with the X-linked form are characterized spectroscopically by the absence of a unique cytochrome $b_{558}$ (11). Most patients with the autosomal recessive form have phagocytes that do contain the membrane-associated cytochrome $b_{558}(29,30)$. Recently, the gene deleted in cells from a patient with X-linked CGD has been identified and sequenced (15). The gene encodes a $91-\mathrm{kD}$ glycosylated protein which is transcriptionally regulated by IFN- $\gamma(24)$. The gene product in the cell associates with a $22-\mathrm{kD}$ constitutively expressed protein forming a complex associated with the cytochrome $b_{558}$ spectrum (16). The precise role of the cytochrome $b_{558}$ in the production of $\mathrm{O}_{2}^{-}$by phagocytes has not been conclusively established, but a considerable body of evidence indicates that the cytochrome $b_{558}$ is the last component of a short electron transport chain for the transfer of reducing equivalents from NADPH to molecular oxygen by a membrane-bound oxidase (reviewed in reference 31). Confounding this issue is the finding that the 91-kD X-chromosome-derived component of the cytochrome $b_{558}$ complex exhibits no significant similarities to other known cytochromes at the amino acid sequence level (15), although the 22-kD component with which it associates does contain a 31-amino acid stretch of $39 \%$ identity with polypeptide I of mitochondrial cytochrome $c$ oxidase (16). To add to this complexity, deficiencies in the phosphorylation of specific proteins after stimulation of PMNs have been demonstrated in both the $\mathrm{X}$-linked and autosomally transmitted forms of CGD, which may be critically involved in the production of cytocidal oxygen metabolites (32).

Although much has been learned from the study of primary cells from patients with CGD, direct analysis is intrinsically difficult due to the paucity of patients with this rare genetic disease, limitations in obtaining sufficient quantities of 
cells from these generally ill, young patients, and the limited survival in culture of primary cells. Furthermore, if one wants to pursue the mechanisms of the regulation of the macrophage respiratory burst by IFN- $\gamma$, primary cells from blood present the additional problem that they already appear primed in vivo for production of oxygen intermediates by IFN- $\gamma$ or other lymphokines $(1,33)$. Epstein-Barr virus transformed B cell lines have been produced from CGD patients as somatic cell models to study this disease; however, transformed B cell lines produce very little superoxide after PMA stimulation (less than one tenth the amount generated by macrophages) (34). These results suggest that cell-specific regulation may be crucial for understanding the oxidative mechanisms of macrophages.

The alternative available to us was the study of cloned macrophage-like cell lines, and variants derived from them that have somatic defects resembling different forms of CGD. We initially identified a murine macrophage clone J774.16, constitutively competent to generate reactive oxygen intermediates, and selected genetic variants defective in their ability to produce superoxide anion upon appropriate stimulation. In previous studies, we characterized a mutant clone, C3C, that failed to produce detectable $\mathrm{O}_{2}^{-}$upon PMA stimulation (17). Careful spectral analysis of this variant indicated that it produced a cytochrome $b_{558}$, but one that failed to bind carbon monoxide (18). Thus, the first variant probably contained a point mutation in the cytochrome $b_{558}$ and may be analogous to the cytochrome $b_{558}$-positive forms of CGD. In the present work a new variant, D9, was found to exhibit characteristics of mononuclear phagocytes from patients with the cytochrome $b_{558}$-negative form of CGD, which we believe may represent a useful in vitro model for analysis of the function and regulation of the CGD gene. D9 cells are unable to produce $\mathrm{O}_{2}^{-}$after PMA stimulation, and at the molecular level, Northern blot analysis revealed that the mRNA encoded in the $91-\mathrm{kD}$ subunit gene locus was absent in this variant. This is similar to findings that monocytes of three of four extensively characterized CGD patients lacked the transcript of the $91-\mathrm{kD}$ subunit, although no alterations in the structural gene were detectable (15). Thus, most X-linked CGD cells examined have been deficient in the mRNA for the cytochrome, at least before treatment with IFN- $\gamma$, whereas virtually all non-X-linked CGD cells express the cytochrome. Although the analogy suggests that the defect in the D9 cells will parallel those found in $\mathrm{X}$-linked CGD cells, and likely be associated with expression of the murine cytochrome, further experiments are clearly required to localize the molecular defect in the D9 mutant cells.

Finally, we describe a third class of mutants here that are constitutively unable to produce $\mathrm{O}_{2}^{-}$, but can be induced to do so by exposure to IFN- $\gamma$, analogous to a form of CGD that is responsive to treatment with $\operatorname{IFN}-\gamma(25,26)$. These findings, together with those indicating that IFN- $\gamma$ can activate a PKCmediated pathway involved in the oxidative burst and induce $\mathrm{O}_{2}^{-}$production in phagocytes of some patients with CGD, suggest that the genetic defects in CGD patients may either be structural or regulatory. With the availability of the cloned genes for the two chains associated with the CGD gene product, the mouse macrophage mutants analogous to different forms of human CGD could prove useful for understanding possible tissue-specific requirements for functional reconstitution of macrophage oxidative functions in gene-transfer experiments.

\section{Acknowledgments}

We express our appreciation to Dr. Jack Peisach for helpful discussions. The DNA probe for the murine homologue of the human CGD gene was generously provided by Dr. J. Fisherman and Dr. S. Orkin, and the IFN- $\gamma$ for these experiments was generously provided by Dr. Michael Shepard and Genentech Inc. Dr. B. Diamond kindly provided the Bac1.2.5 cell line. Rat embryo fibroblast cells were available on a continual basis through the generosity of Dr. M. Scharff. The data in this paper are from a thesis (Dr. M. Goldberg) to be submitted in partial fulfillment of the requirements for the degree of Doctor of Philosophy in the Sue Golding Graduate Division of Medical Sciences, Albert Einstein College of Medicine, Yeshiva University.

This work was supported by National Institutes of Health (NIH) grants AI-07118, 09807, 02111, and NIH T32 GM-7288.

\section{References}

1. Nathan, C. F., H. W. Murry, M. E. Wiebe, and B. Y. Rubin. 1983. Identification of interferon gamma as the lymphokine that activates human macrophage oxidative metabolism and antimicrobial activity. J. Exp. Med. 158:670-689.

2. Murry, H. W., G. I. Byrne, C. D. Rothermal, and D. M. Cartelli. 1983. Lymphokine enhances oxygen-independent activity against intracellular pathogens. J. Exp. Med. 158:235-239.

3. Nathan, C. F., T. J. Prendergast, M. E. Wiebe, E. R. Stanly, E. Platzer, H. G. Remold, B. Y. Rubin, and H. W. Murry. 1984. Activation of human macrophages. Comparison of other cytokines with interferon-gamma. J. Exp. Med. 160:600-605.

4. King, D. P., and P. P. Jones. 1983. Induction of Ia and H-2 antigens on a macrophage cell line by immune interferon. J. Immunol. 131:315-319.

5. Steeg, P. S., R. N. Moore, H. M. Johnson, and J. J. Oppenheim. 1982. Regulation of murine macrophage Ia antigen expression by a lymphokine with immune interferon activity. J. Exp. Med. 156:17801788.

6. Guyre, P. M., P. M. Morganelli, and R. Miller. 1983. Recombinant immune interferon increases immunoglobulin $\mathrm{G} F \mathrm{~F}$ receptors on cultured human mononuclear phagocytes. J. Clin. Invest. 72:393-397.

7. Vogel, S. N., E. A. Havell, and G. L. Spitalny. 1986. Monoclonal antibody-mediated inhibition of interferon gamma induced macrophage antiviral resistance and surface antigen expression. J. Immunol. 136:2917-2923.

8. Goldberg, M., Y. Nagata, and B. R. Bloom. 1985. IFN alpha and IFN gamma inhibit the growth of macrophage cell lines and variants by different mechanisms. The Interferon System. 24:349-353.

9. Holmes, B., R. Page, and R. A. Good. 1967. Studies on the metabolic activity of leukocytes from patients with a genetic abnormality of phagocytic function. J. Clin. Invest. 46:1422-1432.

10. Johnston, R. B., and R. L. Baehner. 1971. Chronic granulomatous disease: correlation between pathogenesis and clinical findings. Pediatrics. 48:730-739.

11. Segal, A. W., A. R. Cross, R. C. Garcia, N. Borregard, N. H. Valerius, J. F. Soothill, and O. T. G. Jones. 1983. Absence of cytochrome-245 in chronic granulomatous disease. N. Engl. J. Med. 308:245-251.

12. Hamers, M. N., M. de Boer, L. J. Meerhof, R. S. Weening, and D. Roos. 1984. Complementation in monocyte hybrids revealing genetic heterogeneity in chronic granulomatous disease. Nature (Lond.). 307:553-555.

13. Orkin, S. H. 1989. Molecular genetics of chronic granulomatous disease. Annu. Rev. Immunol. 7:277-307.

14. Curnutte, J. T. 1988. Classification of chronic granulomatous disease. Hematology/Oncology Clinics of North America. 2:241-252.

15. Royer-Pokora, B., L. M. Kunkel, A. P. Monaco, S. C. Goff, P. E. Newburger, R. L. Baehner, F. S. Cole, and S. H. Orkin. 1986. Cloning the gene for an inherited human disorder-chronic granulo- 
matous disease-on the basis of its chromosomal location. Nature (Lond.). 322:32-37.

16. Parkos, C. A., M. C. Dinauer, L. E. Walker, R. A. Allen, A. J. Jesaitis, and S. H. Orkin. 1988. The primary structure and unique expression of the 22 kilodalton light chain of human neutrophil cytochrome b. Proc. Natl. Acad. Sci. USA. 85:3319-3323.

17. Damiani, G., C. Kiyotaki, W. Soeller, M. Sasada, J. Peisach, and B. R. Bloom. 1980. Macrophage variants in oxygen metabolism. $J$. Exp. Med. 152:808-822.

18. Kiyotaki, C., J. Peisach, and B. R. Bloom. 1984. Oxygen metabolism in cloned macrophage cell lines: glucose dependence of superoxide production, metabolic and spectral analysis. J. Immunol. 132:857-866.

19. Tanaka, Y., H. Tanowitz, and B. R. Bloom. 1983. Growth of Trypanosoma cruzi in a cloned macrophage cell line and in a variant defective in oxygen metabolism. Infect. Immun. 41:1322-1331.

20. Kiyotaki, C., and B. R. Bloom. 1984. Activation of murine macrophage cell lines. Possible involvement of protein kinases in stimulation of superoxide production. J. Immunol. 133:923-931.

21. Nagata, Y., O. M. Rosen, M. H. Makman, and B. R. Bloom. 1984. Biochemical analysis of mutants of a macrophage cell line resistant to the growth-inhibitory activity of interferon. J. Cell Biol. 98:1342-1347.

22. Nishizuka, Y. 1984. Role of protein kinase $C$ in cell surface signal review for showing PMA binding to pkc-high affinity receptor transduction and tumour promotion. Nature (Lond.). 308:693-698.

23. Fan, X. D., M. Goldberg, and B. R. Bloom. 1988. Interferongamma-induced transcriptional activation is mediated by protein kinase C. Proc. Natl. Acad. Sci. USA. 85:5122-5125.

24. Newburger, P. E., R. A. B. Ezekowitz, C. Whitney, J. Wright, and S. H. Orkin. 1988. Induction of phagocyte cytochrome b heavy chain gene expression by interferon gamma. Proc. Natl. Acad. Sci. USA. 85:5215-5219.

25. Ezekowitz, R. A. B., M. C. Dinauer, H. S. Jaffe, S. H. Orkin, and P. E. Newburger. 1988. Partial correction of the phagocyte defect in patients with $\mathrm{X}$-linked chronic granulomatous disease by subcutaneous interferon gamma. $N$. Engl. J. Med. 319:146-151.

26. Sechler, J. M. G., H. L. Malech, J. White, and J. I. Gallin. 1988. Recombinant human interferon-gamma reconstitutes defective phagocyte function in patients with chronic granulomatous disease of childhood. Proc. Natl. Acad. Sci. USA. 85:4874-4878.

27. Goldberg, M., L. S. Belkowski, and B. R. Bloom. 1989. Regulation of macrophage growth and antiviral activity by interferon-gamma. J. Cell Biol. 109:1331-1340.

28. Hamilton, T. A., D. L. Becton, S. D. Somers, P. W. Gray, and D. O. Adams. 1985. Interferon gamma modulates protein kinase $C$ activity in murine peritoneal macrophages. J. Biol. Chem. 260:13781381.

29. Bohler, M.-C., R. A. Seger, R. Mouy, E. Vilmer, A. Fischer, and C. Griscelli. 1986. A study of 25 patients with chronic granulomatous disease: a new classification by correlating respiratory burst, cytochrome $b$ and flavoprotein. J. Clin. Immunol. 6:136-145.

30. Curnutte, J. T., R. L. Berkow, and R. L. Roberts. 1988. Chronic granulomatous disease due to a defect in the cytosolic factor required for NADPH oxidase activation. J. Clin. Invest. 81:606-610.

31. Babior, B. M. 1987. The respiratory burst oxidase. Trends Biochem. Sci. 12:241-243.

32. Okamura, N., J. T. Curnette, R. L. Roberts, and B. M. Babior. 1988. Relationship of protein phosphorylation to the activation of the respiratory burst in human neutrophils. J. Biol. Chem. 263:67776782.

33. Bancroft, G. J., R. D. Schreiber, G. C. Bosma, M. J. Bosma, and E. R. Unanue. 1987. A T cell-independent mechanism of macrophage activation by interferon-gamma. J. Immunol. 139:1 104-1107.

34. Volkman, D. J., E. S. Buescher, J. I. Gallin, and A. S. Fauci. 1984. B cell lines as models for inherited phagocytic diseases: abnormal superoxide generation in chronic granulomatous disease and giant granules in Chediak-Higashi Syndrome. J. Immunol. 133:3006-3009. 